\title{
Motor Learning of a cognitive-motor task after stroke
}

http://dx.doi.org/10.11606/1807-5509202000010001

\author{
Camila TORRIANI-PASIN" \\ Gisele Carla dos Santos PALMA* \\ Cristiane Matsumoto JAKABI** \\ Cinthya WALTER ${ }^{* * * *}$ \\ Andrea Michele FREUDENHEIM* \\ Umberto César CORREA*
}

*School of Physical Education and Sports, University of Sao Paulo, São Paulo, SP, Brazil.

**United Metropolitan Colleges, São Paulo, SP, Brazil.

${ }^{* * *}$ Department of Physical Education, Federal University of Maranhão, São Luís,

MA, Brazil.

\section{Abstract}

The aim of this study was investigated a maze learning in stroke individuals. Forty participants assigned into two groups: experimental (stroke participants; $n=20$ ) and control (neurologically healthy participants; $n=20$ ). The study involved an acquisition phase, a transfer test, and a short-and longterm retention tests. The task consisted in complete a maze, with paper and pen, in the shortest time possible. The dependent variables were execution time and error. Data were analyzed with an Anova- two way with Repeated Measures for these variables. Results showed learning for both groups, but with the experimental group having worse performance compared to control group mainly related error. It was also seen the impact promoted in the task has impaired both groups in the transfer test performance.

KEYwords: Motor Learning; Maze Learning; Cognitive Demand; Stroke.

\section{Introduction}

Strokes are the main cause of chronic disabilities among neurological diseases in many countries. It is acknowledged that more than $50 \%$ of the subjects with strokes present severe physical and cognitive disabilities ${ }^{1,2}$.

The clinical impairments of these subjects are diversified because it might involve different systems (musculoskeletal, cognitive, sensory, and perceptual) which may affect a range of capacities, including the learning of new skills or the use of skills acquired previously to the vascular event ${ }^{2,3}$. In this context, research in the Motor Learning area could provide a basis for better understand the underlying processes, and to generate useful insights for the development of intervention programs for subjects affected by brain injury.

Although in the last few years the research interest in motor skill learning of subjects with neurological injuries has increased ${ }^{4-7}$, it seems that there is a lack of consensus regarding the learning deficit. For instance, while some claim that there is no learning impairment after a stroke ${ }^{2}$, others argue that there are lesion topographies that are more likely to impair, but not prevent the occurrence of motor learning ${ }^{8}$. And still there are others who say that there is no impairment on the learning motor tasks after stroke ${ }^{3,9-14}$.

Some researchers have suggested that motor learning in stroke individuals is influenced by the severity of the injury, high degree of severity may be impaired in terms of learning new skills ${ }^{10,13}$. Still, the side of the injury has also been reported as a factor influencing the occurrence of post-stroke motor learning ${ }^{15}$, suggesting that patients with damage to the left hemisphere have impaired motor skill planning ${ }^{16}$.

In this controversial context, some methodological flaws it is noticed. While in some studies, motor learning was only measured through retention test ${ }^{4,12,13,17}$, in others, the experimental design did not include a healthy control group ${ }^{12,13}$. In addition, the task demand in the above-mentioned studies is essentially effector. These studies also cite the important task 
dimensions implied in the learning of the stroke patients ${ }^{16}$, as tasks with high cognitive demand, especially for planning, decision-making and problem-solving. The hypothesis of this study was that motor learning capacity is intact in stroke patients, however the level of performance when compared with healthy subjects, it will be impaired. The particular interest is to investigate learning through the transfer test and its retention in short and long term. Therefore, the aim of this study was to investigate the learning of cognitive-motor skill in stroke individuals comparing their performance to neurologically healthy individuals.

\section{Method}

This study was approved by the local Ethics Committee of the Institution, under number 13363343. All study's participants or their legal guardians read and signed a free and informed consent form which was duly explained when necessary.

\section{Participants}

The two sample groups were the experimental (EG) and control (CG). The EG involved of 20 (6 females and 14 males) hemiparetic or hemiplegic stroke individuals with a mean age of 54,9 years (SD $=10.7)$. The sample was chosen by convenience and gender was not a determining factor into account during the recruitment.

The participants were in a rehabilitation process, but not during the week of evaluation and practice of task. They matched according to the age and MMSE. The exclusion criteria included aphasia, apraxia, neglect, clinical instability and other associated neurological diseases (e.g., Parkinson's Disease and Dementia, Alzheimer's).

The CG involved 20 healthy participants (13 males and 7 females) with no neurological disorders with a mean age of 5,9 years $(S D=12.2)$. All of the subjects were right-handed, which dominance was determined by the Edinburgh Handedness Inventory ${ }^{18}$. All of the subjects scored at or above 23 points on the Mini Mental State Examinatio ${ }^{19}$ (MMSE) and these data were used for sample characterization.

For the EG group, the Orpington Prognostic Scale ${ }^{20}$ used in order to classify the disabilities that resulted from the stroke. This classification included the evaluation of upper limb motor deficits, proprioception, balance and cognition. The subjects of the EG were classified according to the following points: 1.6 to $3.1=$ mild; 3.2 to $5.2=$ moderate; and, from 5.2 upwards = severe. Experimental group classified by Orpington Scale as follow: 7 mild, 12 moderate and 1 severe.

\section{Task and material}

The maze task was used because it involves cognitive (e.g., planning, decision-making and problem solving) and motor (e.g., it was performed with the less-affected arm) demands. Furthermore, this task presents feasibility, ease of application and adaptability to diverse populations ${ }^{21,22}$. The task consisted of drawing a path on a paper using a pen that led out of the maze in the shortest time possible. The maze task always had a single solution. The collecting data took around 40 minutes in the first phase and 10 minutes in the second phase.

The time spent on each trial measured by a Sanny (Sport Timer) digital timer and initialized manually by the examiner. The error was detected when the subject chooses the wrong pathway and was not able to finish the maze. It was measured through the number of occurrences by the examiner.

\section{Procedures}

The experiment consisted of four phases: acquisition (A), transfer (TR), short-term retention (S-RET), and long-term retention (L-RET). In the $A$, the participants performed six blocks of five trials practicing the maze (A). After five minutes, the participants performed the TR test (B) which consisted of five trials in a new maze task. For this purpose, the exit of the maze modified, which implied in making-decision of new internal routes. The S-RET test performed five minutes after the TR test (with the maze - B). It consisted of five trials of the same transfer task. Finally, after two days the participants performed the L-RET with the same task of the previous test (with the maze - B).

Data collection conducted in a closed room 
with one participant at a time. The beginning of the experiment preceded by a prerecorded verbal explanation, so that all of the subjects received the same instructions. The recording included the following instructions: "You will perform a task that is called maze. This figure has only one entrance and one exit. You must make a line with a pen to identify the exit route in the shortest time possible, using your non-affected hand. Start the task upon the signal given by the experimenter. Activate a timer when you started, and it will be stopped only at the end of the performance. If you trace the wrong pathway, go back to the beginning." Participants also informed that they could not see the maze before they began the trial.

\section{Measures}

The main outcome was time to complete the task; this variable reflects the goal task achievement. The secondary outcome was error and provides complementary information about how the goal of task was achieved.

\section{Results}

The sample characterization is shown in TABLE 1. In general, the sample was composed of individual with chronic stroke, 54 years, in major male, with moderate impairment and left side lesion.

The time variable is represented on the FIGURE 1A. It shows that in all acquisition blocks both groups achieved similar performance, but the EG had a minor magnitude compared the CG. It also shows that the EG, in acquisition phase, diminished the execution time from 20 to 13 seconds, and the CG diminished

\section{Analysis}

SPSS Statistics version 22 (IBM, USA) was used to run the data. The Shapiro-Wilk's and Levene's tests confirmed normality and homogeneity data, respectively, and parametric analysis was performed.

The data related to time were analyzed in blocks of five trials regarding the performance's magnitude (mean) and variability (standard deviation) as the dependent variable. The data related to error were analyzed in blocks of five trials regarding the performance's magnitude (total) and variability (standard deviation). Performance was analyzed considering the acquisition and the transfer and retention blocks through a two-way ANOVA (2 Groups x 9 Blocks) with repeated measures on the second factor $^{23}$. Observed effects were followed up by Turkey post-hoc tests. For all analyses, the effect size was required. And the level of significance adopted was alpha $<0.05$.

from 13 to 8 seconds. In relation to the tests, FIGURE 1A shows that they were disturbed by the introduction of a new task (transfer block), but that they recovered the performance's levels following a few attempts of retention tests. The inferential analysis revealed significant effects between groups $(F=7,34, p<0.010, \mathrm{ES}=0.75)$ and within groups $(F=12,20, p<0.001$, Effect size $(E S)=0.92)$. The post-hoc test indicated that the difference was in TR $(F=6,14, p=0.018$, $E S=0.68)$, S-RET $(F=9,34, p=0,004, E S=0,84)$ L-RET $(F=5,14, p=0.029, E S=0.59)$.

TABLE 1 - Sample characteristics.

\begin{tabular}{|c|c|c|c|c|c|c|}
\hline Group & $\begin{array}{l}\text { Time since } \\
\text { Lesion } \\
\text { (months) }\end{array}$ & $\begin{array}{c}\text { Age } \\
\text { (years) }\end{array}$ & Gender & Side of lesion & MMSE (score) & $\begin{array}{c}\text { Orp } \\
\text { (classif.) }\end{array}$ \\
\hline $\begin{array}{l}\text { Experimental } \\
\text { Group }\end{array}$ & 58,5 & 54,9 & Male $(14 / 20)$ & Left $(11 / 20)$ & 26 & Mild $(7 / 20)$ \\
\hline \multirow[t]{2}{*}{ Mean (SD) } & $(78,7)$ & $(10,7)$ & Female $(6 / 20)$ & Right $(9 / 20)$ & (3) & $\begin{array}{c}\text { Moderate } \\
(12 / 20)\end{array}$ \\
\hline & & & & & & Severe $(1 / 20)$ \\
\hline Control Group & --- & 59 & Male $(13 / 20)$ & --- & 27 & --- \\
\hline Mean (SD) & --- & $(12,2)$ & Female $(7 / 20)$ & --- & (3) & \\
\hline
\end{tabular}

MEEM (Mini Mental State Exam). Data are presented in Mean (Standard Deviation).

In Gender, and Orp (Orpington Scale) (classification) data are presented in absolute number. 


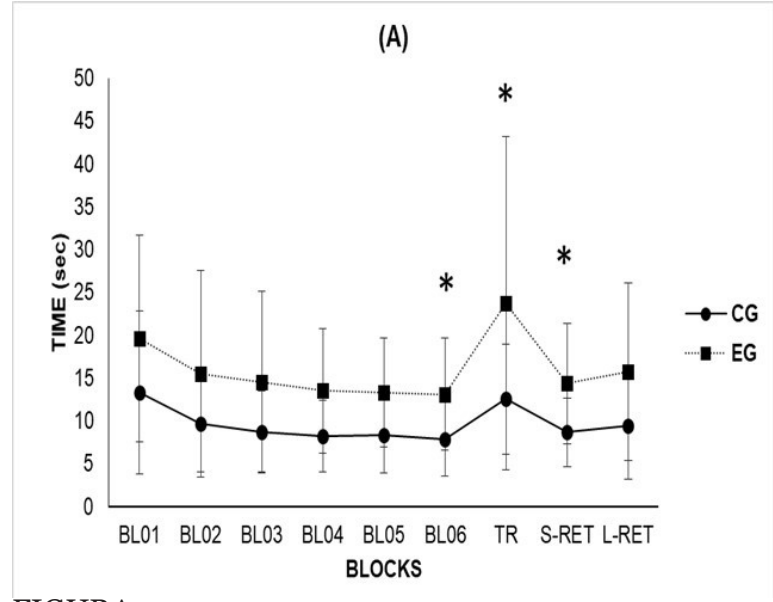

FIGURA 1

The error variable is represented on the FIGURE 1B, it shows that both groups diminished error over time. Additionally, the magnitude of error was bigger in EG. The groups had a similar performance from block 1 to 5 , decreasing the error. It also shows that in acquisition phase the EG diminished the error from 20 in BL01 to 5 in BL06, and the CG diminished from 6 to 0 in
(B)

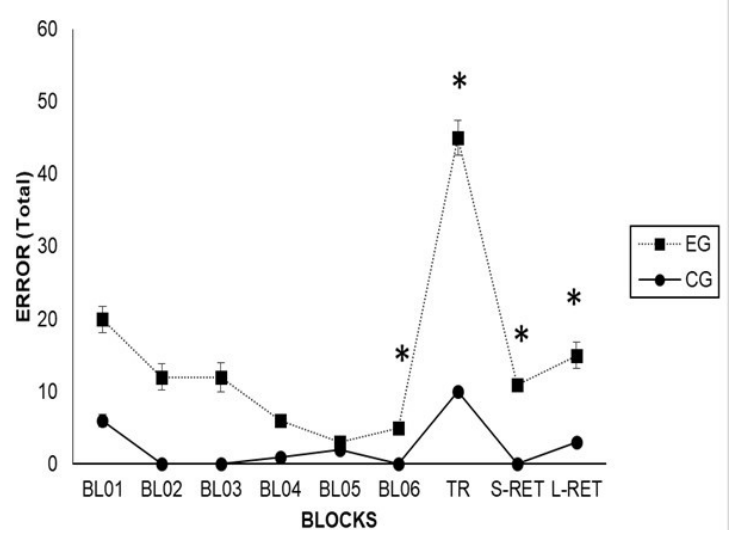

the same blocks. The inferential analysis revealed significant effects between groups $(F=5,83, p=$ $0.021, E S=0.65)$ and within groups $(F=9,10, p=$ $0.000, E S=0.99)$. The post-hoc tests indicated that the difference between groups was in BL $06(F=$ $8,60, p=0.006, E S=0.81)$, TR $(F=10,32, p=0.003$, $E S=0.67), S-R E T(F=9,39, p=0.004, E S=0.84)$ and L-RET $(F=5,14, p=0.029, E S=0.59)$.

\section{Discussion}

The aim of this study was to investigate the learning of a task with cognitive-motor demand in stroke indivuduals.

The results from the main variable show that stroke subjects can learn a cognitive-motor skill. Two questions will guide the discussion: (A) How occurred the learning of stroke subjects? (B) Is there a difference between the learning of this task of healthy subjects and stroke subjects? The following discussion is organized around these issues.

\section{How occurred the learning of stroke subjects?}

In order to respond to this question, it is necessary to confirm that the task learning occurred in each group. Based on the main variable, the intragroup analysis indicates that there was a decrease in the time at A for both groups over the blocks of trials, therefore there was significant improvement of performance during acquisition.

The same occurred for the secondary outcome, where the EG diminished error over to A phase. However, there was no maintenance of performance at TR, which might suggest that the modifications imposed on the TR were very strict, relative to the task practiced in the $\mathrm{A}$, which may have led to the failure of the subjects to transfer what they have learned. However, when analyzing the S-RET performance, it is evident that there was learning because they recovered the performance quickly, with a few attempts, and this indicates the occurrence of learning.

The subjects likely used the practice trials provided during the TR (a block of 5 trials only) to improve their performance in the subsequent S-RET. However, in terms of error, EG were not able to achieve the same performance level at BL06. Even though the EG could adapt quickly and present a maintenance of the performance similar to the middle blocks of acquisition.

Once the subjects learned the most appropriate solution (in less time and few or no errors) out of the maze, they were able to reproduce the task in later trials. Therefore, regarding the TR it would 
be possible to affirm that there was an impact in the learning of stroke subjects. However, considering all the tests, TR, S-RET and L-RET (see FIGURE), we can see the higher performance in S-RET compared to the TR. These findings indicate a quick recovery of performance from TR to S-RET, after a small amount of practice. Besides, in terms of time, comparing S-RET and L-RET there was maintenance of performance for both groups.

The complementary measure chosen does not confirm theses results. In terms of error, the EG did not kept the level of performance comparing S-RET with L-RET. This result suggests that there is a potential to learn a new motor skill preserved in stroke. However, according to the deterioration of performance comparing the S-RET with the L-RET, we could affirm that memory is impaired after stroke. This finding was also seen by other studies in which the maintenance of performance is not achieved through the time with no practice $e^{11,24}$.

Possible explanations could be that the cognitive impairment in stroke subjects affects recall mechanism ${ }^{25}$. This impairment caused by lesion or by secondary atrophy or neurodegeneration ${ }^{26}$ cause network dysfunction making it difficult to access recall of ability ${ }^{27,28}$. Besides S-RET, the observed behavior of the learning curves for both groups is similar, which suggests the potential for motor skill learning in stroke, as other studies already suggested, with only retention test $\mathrm{t}^{11,12,17}$.

\section{Is there a difference between the learning of this task of healthy subjects and stroke subjects?}

During the acquisition, lower performance scores noted in the stroke compared to healthy subjects, but the groups were different in the last block of acquisition and the learning tests. During the acquisition, however, there was significant improvement in the performance of the subjects in both groups. This indicates that the improvement of performance is dependent on the amount of practice $^{29-31}$ regardless of the presence of injury from a stroke. Therefore, it might be possible to affirm that with more opportunities for practice, there is a tendency for the performance of subjects to approach and converge in a similar pattern. Such trends are especially noted within the EG rather than in the CG, which explains why there is greater need for practice among stroke than among healthy subjects for the same task ${ }^{32}$.
A significant difference seen between the groups on the learning tests indicate that after a stroke, even the performance of a task with the less affected upper limb may be difficult, especially considering injuries in the sensory-motor cortical areas and its interaction with manual dominance. Considering these cerebral areas, injury often affects both memory and executive functioning ${ }^{31}$ which could affect information process and can affect both memory and executive functions. A study that ${ }^{24}$ evaluated verbal and visuospatial memory and attention, planning, mental flexibility and problem-solving ability in this population and they argue that the ability to build strategies involved in implicit motor learning can be impaired due to these reasons. This would explain why participants in EG, although able to enhance their performance, could not match the performance showed by CG.

Furthermore, other study ${ }^{33}$ investigating whether stroke doing rapid target tasks using the less affected limb improved performance compared with healthy subjects. The authors concluded that both groups (EG and $\mathrm{CG}$ ) improved performance with practice, but that the EG needed more time to complete the task, which showed a change in control and not in the learning process itself $^{12,30}$. These studies corroborate the findings of the present study in that practice improves performance during the acquisition, and that the performance levels achieved by the EG are lower and more variable than the CG.

These results suggest that not all stroke are capable of demonstrating similar levels of learning through different implicit motor tasks ${ }^{13}$. Some subjects with moderate to severe damage (measured by the Orpington scale) have impairment in learning a motor skill, which is not seemed on mild stroke subjects. In our study, the sample was mainly mild impaired, which can justify our results ${ }^{12}$.

No single lesion or disease process completely abolishes the ability to learn and remember motor skills implicitly ${ }^{17}$, since it is known that many factors can influence in motor learning. Cognition and memory are certainly important to this process and our results may indicate that there is a similarity in the central motor learning (e.g., encoding and memory) between both groups, as the curves were similar and the learning process seems to be preserved in these subjects ${ }^{34}$.

A study that ${ }^{34}$ investigated whether a unilateral lesion affected the performance and learning 
of fast programmed actions. The task was to perform a discrete coordinated movement of specific amplitude with the upper limb. The results indicated that even though the processes involved in the control and the execution of motor skills is affected in stroke subjects the ability to learn these skills is still intact. In the present study, the investigated task classified as a predominant cognitive demand, including planning, decisionmaking and problem solving. Therefore, it might be possible to suggest that the learning preserved in post-stroke patients as well as the possibility to make use of those cognitive substrates to solve problems for achieve the best solution for the maze task, especially considering the stroke patients performed the task with the less-affected arm. The performance with the less-affected arm allows the distinction between the motor control impairment and the implicit learning impairment.

The increased performance time during the TR can also explained by the structure of practice offered to the groups. Some studies in the literature show that subjects who are submitted to the tasks randomly in the acquisition phase transferred the skills they learned better than those who practice the tasks constantly ${ }^{29,33,35}$. So that, although the practice structure was not investigated at this study, it might be possible to speculate that the deterioration in performance observed during the TR by the EG may reflect the idea that learning can be compromised or influenced by the structure of practice implemented during the acquisition, which was constant in the present study (not random).

Transfer refers to the ability of plasticity within a range of neural circuits to promote concurrent or subsequent plasticity ${ }^{7,14,25,36-38}$. In the transfer test is the influence of a previously practiced skill about learning a skill like ${ }^{31}$.

Another important point regarding the heterogeneity of the performance in stroke could be the severity of the lesion. The EG consisted of subjects with mild, moderate and severe cerebral vascular injuries, which may affect the validity of the results related to learning and maybe, could explain the heterogeneity of the performance in the T-test, as seen in a study ${ }^{13}$.

The task selected allowed to assess the capacity of subjects to develop a plan of action through the selection of solutions most appropriate for its performance. Evaluating the characteristics of solving these tasks is challenging in patients with lesions in the area of the anterior circulation. The skills needed to solve these tasks are similar to those found in many everyday situations. The ecological validity of these characteristics, however, is limited because they do not match the actual form of the tasks performed in day-to-day life.

The fact that EG is composed by individuals with mild, moderate and severe is a factor that interferes with the results related to learning as known ${ }^{32,39}$. So that, as a suggestion to continue investigating the theme, we suggest to assess the effect of injury severity as an independent variable, and therefore as a criterion for training groups in order to guarantee a representative number of individuals with different levels of damage in each group.

Corroborating these assumptions, a study ${ }^{8}$ describes that stroke are able to learn new skills ${ }^{3}$, however, implicit motor learning may be impaired, particularly those with lesions in the front-temporal lobe (area irrigated by anterior circulation, as well as the participants of this study). Which in our work was not seemed, because the participants were able to learn in when compared to the control group participants.

Finally, note that the fact that there is improvement in performance during acquisition does not guarantee good transferability to a similar ability $^{29}$, since the phase difference was observed TR statistically significant increase with time relative to BL6 and A phase. Accordingly, the EG held in a longer time relative the CG due to disturbance offered to groups by shifting the task at S-RET. The EG was more sensitive to change and had more difficulties to adapt during TR.

Increased time on stage TR can also be explained by the structure of practice offered to groups, since subjects undergoing random tasks with practice in the skill transfer A better than those who perform constant practice, as several studies $^{30,31,35}$. This finding regarding the large deterioration in performance observed in the TR on the EG may reflect the idea that learning can be somehow compromised or heavily influenced by the structure of practice provided in the A.

In conclusions, the implicit learning of a predominant cognitive demand skill, as measured by retention tests, is preserved in stroke. Stroke individuals have improved motor skill performance as a function of practice, but this improved performance remains at a level below the motor skill performance of the healthy subjects, including more errors. 


\section{Resumo}

Aprendizagem Motora de uma tarefa cognitivo-motora após o AVC

Este estudo investigou a aprendizagem de uma tarefa cognitivo-motora pós-Acidente Vascular Cerebral. Quarenta participantes foram divididos em dois grupos: experimental (sujeitos pós-AVC; $n=20$ ) e controle (participantes neurologicamente saudáveis; $n=20$ ). 0 estudo envolveu uma fase de aquisição, um teste de transferência e testes de retenção de curto e de longo prazo. A tarefa consistiu completar um labirinto, com papel e caneta, no menor tempo possível e a variável dependente foi o tempo e erro de execução. Os dados foram analisados por meio de uma Anova-two way com medidas repetidas para ambas variáveis. Os resultados mostraram aprendizagem para ambos os grupos, mas com o grupo experimental com pior desempenho comparado ao grupo controle, principalmente relacionado ao erro. Entretanto, a perturbação promovida na tarefa prejudicou ambos os grupos no desempenho do teste de transferência.

PalavRas-Chave: Aprendizagem Motora; Aprendizagem em Labirinto; Demanda Cognitiva; Acidente Vascular Cerebral.

\section{References}

1. Ovbiagele B, Goldstein LB, Higashida RT, Howard VJ, Johnston SC, Khavjou O, et al. Forecasting the future of stroke in the united states: A policy statement from the American heart association and American stroke association. Stroke. 2013;44:2361-75.

2. Go AS, Mozaffarian D, Roger VL, Benjamin EJ, Berry JD, Blaha MJ, et al. Heart disease and stroke statistics--2014 update: a report from the American Heart Association. Circulation [Internet]. 2014[cited 2014 Jul 9];129(3):e28-292. Available from: http://www.ncbi.nlm.nih.gov/pubmed/24352519.

3. Bonuzzi GMG, Freitas TB, Corrêa UC, Freudenheim AM, Pompeu JE, Torriani-Pasin C. Learning of a postural control task by elderly post-stroke patients. Motri. 2016;12(1):141.

4. Cauraugh JH, Kim SB. Stroke motor recovery: active neuromuscular stimulation and repetitive practice schedules. J Neurol Neurosurg Psychiatry [Internet]. 2003[cited 2015 Apr 14];74(11):1562-6. Available from: http://jnnp.bmj. com/content/74/11/1562.short.

5. Platz T, Denzler P, Kaden B, Mauritz K-H. Motor learning after recovery from hemiparesis. Neuropsychologia [Internet]. 1994[cited 2015 Jul 6];32(10):1209-23. Available from: http://www.sciencedirect.com/science/article/ pii/0028393294901031.

6. Proffitt R, Lange B, Chen C, Winstein C. A Comparison of Older Adults' Subjective Experience With Virtual and Real Environments During Dynamic Balance Activities. J Aging Phys Act. 2015;23(1):24-33.

7. Winstein CJ, Kay DB. Translating the science into pratice: shaping rehabilitation pratice to enhance recovery after brain damage. Prog Brain Res. 2015;218:331-60.

8. van Vliet PM, Wulf G. Extrinsic feedback for motor learning after stroke: what is the evidence? Disabil Rehabil [Internet]. 2006[cited 2014 Aug 29];28(13-14):831-40. Available from: http://www.ncbi.nlm.nih.gov/pubmed/16777770.

9. Gharbawie OA, Whishaw IQ. Parallel stages of learning and recovery of skilled reaching after motor cortex stroke: "oppositions" organize normal and compensatory movements. Behav Brain Res [Internet]. 2006[cited 2015 Jul 6];175(2):249-62. Available from: http://www.sciencedirect.com/science/article/pii/S0166432806004876.

10. Orrell AJ, Eves FF, Masters RSW. Motor learning of a dynamic balancing task after stroke: implicit implications for stroke rehabilitation. Phys Ther. 2006;86(3):369-80.

11. Pohl PS, McDowd JM, Filion DL, Richards LG, Stiers W. Implicit learning of a perceptual-motor skill after stroke. Phys Ther [Internet]. 2001[cited 2015 Feb 23];81(11):1780-9. Available from: http://www.ncbi.nlm.nih.gov/ pubmed/11694171.

12. Pohl P, McDowd J, Filion D, Richards L, Stiers W. Implicit learning of a motor skill after mild and moderate stroke. Clin Rehabil [Internet]. 2006[cited 2015 Feb 19];20(3):246-53. Available from: http://cre.sagepub.com/content/20/3/246. short. 
13. Boyd L, Quaney BM, Pohl PS, Winstein CJ. Learning implicitly: effects of task and severity after stroke. Neurorehabil Neural Repair [Internet]. 2007[cited 2014 Aug 26];21(5):444-54. Available from: http://www.ncbi.nlm.nih.gov/ pubmed/17416874.

14. Winstein C, Lewthwaite R, Blanton SR, Wolf LB, Wishart L. Infusing Motor Learning Research Into Neurorehabilitation Practice: A Historical Perspective With Case Exemplar From the Accelerated Skill Acquisition Program. J Neurol Phys Ther. 2014;38(3):190-200.

15. Voos M, Ribeiro do Valle L. Estudo comparativo entre a relação do hemisfério acometido no acidente vascular encefálico e a evolução funcional em indivíduos destros. Rev Bras Fisioter [Internet]. 2008[cited 2015 Jul 6];12(2):113-20. Available from: http://www.scielo.br/scielo.php?script=sci_arttext\&pid=S1413-35552008000200007\&lng=en\&nr $\mathrm{m}=\mathrm{iso} \& \mathrm{t} \operatorname{lng}=\mathrm{en}$.

16. Torriani-Pasin C. Aprendizagem de uma habilidade motora com demanda de planejamento em sujeitos pós Acidente Vascular Encefálico em função do lado da lesão [Internet]. São Paulo: Universidade de São Paulo; 2010. Available from: http://www.teses.usp.br/teses/disponiveis/39/39132/tde-16082010-153057/pt-br.php.

17. Boyd L, Winstein C. Impact of explicit information on implicit motor-sequence learning following middle cerebral artery stroke. Phys Ther [Internet]. 2003[cited 2014 Sep 19];83(11):976-89. Available from: http://ptjournal.apta. org/content/83/11/976.short.

18. Oldfield RC. The assessment and analysis of handedness: the Edinburgh inventory. Neuropsychologia [Internet]. 1971[cited 2017 Dec 14];9(1):97-113. Available from: http://www.ncbi.nlm.nih.gov/pubmed/5146491.

19. Folstein M, Folstein S, McHugh P. Mini-mental state - practical method for grading cognitive state of patients for clinician. J Psychiatr Res. 1975;12(3):189-98.

20. Lai SM, Duncan PW, Keighley J. Prediction of functional outcome after stroke: comparison of the Orpington Prognostic Scale and the NIH Stroke Scale. Stroke [Internet]. 1998[cited 2016 Aug 8];29(9):1838-42. Available from: http:// www.ncbi.nlm.nih.gov/pubmed/9731605.

21. Souza D, França F, Campos T. Teste de labirinto: instrumento de análise na aquisição de uma habilidade motora. Rev Bras Fisioter [Internet]. 2006[cited 2015 Jul 7];10(3):355-60. Available from: http://www.scielo.br/scielo. php?script=sci_arttext\&pid=S1413-35552006000300016\&lng=en\&nrm=iso\&tlng=pt.

22. Sousa DE, Oliveira DC, Campos TF. Maze test: an instrument to evaluate age-related cognitive and motor changes in humans. Rev Bras Ciências do Envelhec Hum. 2013;10(1):19-29.

23. Kal E, Winters M, Van Der Kamp J, Houdijk H, Groet E, Van Bennekom C, et al. Is Implicit Motor Learning Preserved after Stroke? A Systematic Review with Meta- Analysis. PLoS One. 2016;11(12):e0166376. doi: 10.1371/journal. pone. 0166376.

24. Cirstea CM, Ptito A, Levin MF. Feedback and cognition in arm motor skill reacquisition after stroke. Stroke [Internet]. 2006[cited 2015 Apr 14];37(5):1237-42. Available from: http://stroke.ahajournals.org/content/37/5/1237.short.

25. Kantak SS, Winstein CJ. Learning-performance distinction and memory processes for motor skills: a focused review and perspective. Behav Brain Res [Internet]. 2012[cited 2014 Jul 14];228(1):219-31. Available from: http://www. ncbi.nlm.nih.gov/pubmed/22142953.

26. Dichgans M, Leys D. Vascular Cognitive Impairment. Circ Res. 2017;120(3):573-91.

27. Meehan SK, Randhawa B, Wessel B, Boyd LA. Implicit sequence-specific motor learning after subcortical stroke is associated with increased prefrontal brain activations: an fMRI study. Hum Brain Mapp [Internet]. 2011 [cited 2017 Jan 5];32(2):290-303. Available from: http://www.ncbi.nlm.nih.gov/pubmed/20725908.

28. Janacsek K, Nemeth D. Implicit sequence learning and working memory: Correlated or complicated? Cortex [Internet]. 2013[cited 2017 Dec 18];49(8):2001-6. Available from: http://www.ncbi.nlm.nih.gov/pubmed/23541152.

29. Karni A, Meyer G, Rey-Hipolito C, Jezzard P, Adams MM, Turner R, et al. The acquisition of skilled motor performance: fast and slow experience-driven changes in primary motor cortex. Proc Natl Acad Sci U S A [Internet]. 1998[cited 2015 Jul 6];95(3):861-8. Available from: /pmc/articles/PMC33809/?report=abstract.

30. Krakauer JW. Motor learning: its relevance to stroke recovery and neurorehabilitation. Curr Opin Neurol [Internet]. 2006[cited 2015 Feb 23];19(1):84-90. Available from: http://www.ncbi.nlm.nih.gov/pubmed/16415682.

31. Schmidt RA, Wrisberg CA. Aprendizagem e Performance Motora [Internet]. 2nd ed. Porto Alegre: Artmed; 200 [cited 2015 Feb 19]. p. 352. Available from: http://www.livronorte.com.br/books_details.asp?cod_ livro=SC2247\&BOOK=APRENDIZAGEM E PERFORMANCE MOTORA.

32. Dancause N, Ptito A, Levin MF. Error correction strategies for motor behavior after unilateral brain damage: shortterm motor learning processes. Neuropsychologia. 2002;40(8):1313-23. 
33. Pohl PS, Winstein CJ. Practice effects on the less-affected upper extremity after stroke. Arch Phys Med Rehabil [Internet]. 1999 [cited 2015 Feb 19];80(6):668-75. Available from: http://www.sciencedirect.com/science/article/pii/ S0003999399901703.

34. Winstein CJ, Merians S, Sullivan KJ. Motor learning after unilateral brain damage. Neuropsychologia. 1999;37(8):97587.

35. Lee TD, Magill RA, Weeks DJ. Influence of practice schedule on testing schema theory predictions in adults. J Mot Behav [Internet]. 1985 [cited 2015 Jul 6];17(3):283-99. Available from: http://www.ncbi.nlm.nih.gov/pubmed/15140683.

36. Cirstea MC, Levin MF. Improvement of arm movement patterns and endpoint control depends on type of feedback during practice in stroke survivors. Neurorehabil Neural Repair [Internet]. 2007[cited 2015 Apr 14];21(5):398-411. Available from: http://nnr.sagepub.com/content/early/2007/03/16/1545968306298414.short.

37. Kantak SS, Sullivan KJ, Fisher BE, Knowlton BJ, Winstein CJ. Transfer of motor learning engages specific neural substrates during motor memory consolidation dependent on the practice structure. J Mot Behav [Internet]. 2011 [cited 2014 Sep 10];43(6):499-507. Available from: http://www.ncbi.nlm.nih.gov/pubmed/22150021.

38. Kleim JA, Jones TA. Principles of experience-dependent neural plasticity: implications for rehabilitation after brain damage. J Speech Lang Hear Res [Internet]. 2008;51(1):S225-39. Available from: http://www.ncbi.nlm.nih.gov/ pubmed/18230848.

39. Cirstea MC, Ptito A, Levin MF. Arm reaching improvements with short-term practice depend on the severity of the motor deficit in stroke. Exp brain Res [Internet]. 2003[cited 2015 Jul 6];152(4):476-88. Available from: http://www. ncbi.nlm.nih.gov/pubmed/12928760.

\begin{tabular}{r|r} 
CorReSPONDING AUTHOR: & \\
Camila Torriani-Pasin & \\
Av Prof Melo Moraes, 65 - Butantã & Submitted: 29/09/2016 \\
São Paulo - SP - BRAZIL & 1st. Review: 08/01/2018 \\
CEP: 05508-030 & Accepted: 07/03/2018
\end{tabular}

